\title{
NEED OF COMMUNITY BASED SUSTAINABLE APPROACH FOR SOLID WASTE MANAGEMENT IN KATHMANDU
}

\author{
Dinesh C. DEVKOTA ${ }^{1}$ and Kunio WATANABE ${ }^{2}$ \\ ${ }^{1}$ Student Member of JSCE, Doctoral Student, Graduate School of Science and Engineering, Saitama University \\ (255 Shimo - Okubo, Sakura-ku, Saitama City, Saitamaken 338 -8570, Japan) \\ E-mail:ddgorkha@hotmail.com \\ ${ }^{2}$ Member of JSCE, Professor, Geosphere Research Institute, Saitama University \\ (255 Shimo - Okubo, Sakura-ku, Saitamaken 338 -8570, Japan) \\ E-mail:Kunio@post.saitama-u.ac.jp
}

\begin{abstract}
This paper presents the case study on one of the major infrastructure component of urban areas: the solid waste management of Kathmandu valley, Nepal. The community survey conducted in Kathmandu revealed that the traditional solid waste management system lacks a complete awareness and involvement of the community from the planning stage. Planning and developing solid waste management system to date, as a purely technical perspective, has led to the failure of these 'systems' with catastrophic impacts. Hence, there is a need for a major shift in approach 'the community-based' instead of centrally managed to make the service more efficient pertinent to the local needs and conditions.
\end{abstract}

Key Words: infrastructural facilities, mitigative measures, community-based, catastrophic impacts

\section{INTRODUCTION}

Poverty alleviation is the overarching goal of His Majesty's Government of Nepal (HMG/N) and its development partners $\left(\mathrm{NPC}^{1)}\right)$. As such, the infrastructures play a prominent role. In general terms infrastructure denotes all the means, methods and facilities that lead society towards the sustainable socio-economic development. Thus, the word physical infrastructures include human made scientific means and methods including human capital. Improved infrastructure provides widespread benefits for the economy. These benefits as well as their associated costs have to be identified and estimated for the sustainable economic growth of the country. UNEP ${ }^{2)}$ has categorized rural and urban issues in Nepal into three levels based on their urgency. The most urgent first level issues requiring immediate attention are forest depletion; land degradation, solid waste management, waste, and air pollution. The moderate urgency second level issues from the management point of view include dwindling biodiversity, desertification, haphazard urbanization, forest fire, ground water depletion, glacial lake outburst flood event, food security, and alternative energy. The less urgent but significant third level issues in terms of implementing environmental prescription include waning fisheries, decreasing biomass energy, trans-boundary movements of wastes, and noise pollution.

Infrastructures are meant to help people get on with their life by different facilities like communications, buildings, transportation, water supply, electricity, landfill sites and etc but in case of the Nepalese context it often becomes a barrier than an aide. There are no effective rules to ensure accessibility of the built environment. The most difficult obstacles, when planning to build accessible environments, are attitudinal factors, lack of legislation and regulations, lack of user participation, lack of cooperation from other organizations/institutions and lack of enforcement mechanism. There is no awareness component incorporated in the training of planners, architects, environmentalists, and construction engineers to understand the people need in particular.

This paper presents the assessment and the case study on one of the major infrastructure component of urban areas: the solid waste management of Kathmandu valley, Nepal. The paper further explains the solid waste management an urban problem and its policies, present condition and community need identification for community-based solution. 


\section{(1) Solid waste, an environmental problem}

In addition to well-known constraints, there are many other factors acting against effective solid waste management in urban areas of developing countries, some of which are traditional values, religious beliefs and the existing caste system. For example, it is widely believed in Nepal that work requiring direct contact with solid waste is strictly for the lower classes.

Furthermore, the absence of environmental standards in most developing countries has taken the onus away from the Governments on solid waste management. Fig.1 shows the result of survey of 3,980 urban residents from all over Nepal, in which unmanaged waste is considered to be the main environmental and sanitation problem in the country.

In Katmandu valley, solid waste management is extremely poor and recycling of sewerage and industrial waste, particularly doesn't exist. Inadequate processing and improper handling of solid waste is posing a risk to the public health. This is a serious issue and felt the need of sustainable approach for solid waste management.

\section{(2) Policies on solid waste management in Nepal}

In Nepal, the Solid Waste Management and Resource Mobilization Act was formulated in 1987 in order to regulate, collect, recycle and dispose solid wastes generated in the three cities of Kathmandu Valley. It has also emphasized on the provision of construction of public conveniences, bathhouses, mobile public toilets and slaughterhouses at appropriate places. Involvement of private sectors in collection and transportation of solid waste to dumping sites was also encouraged; however this is in the incipient phase. In 1996, the Government took another major step by announcing Solid Waste Management National Policy in order to provide a long-term solution of garbage problems

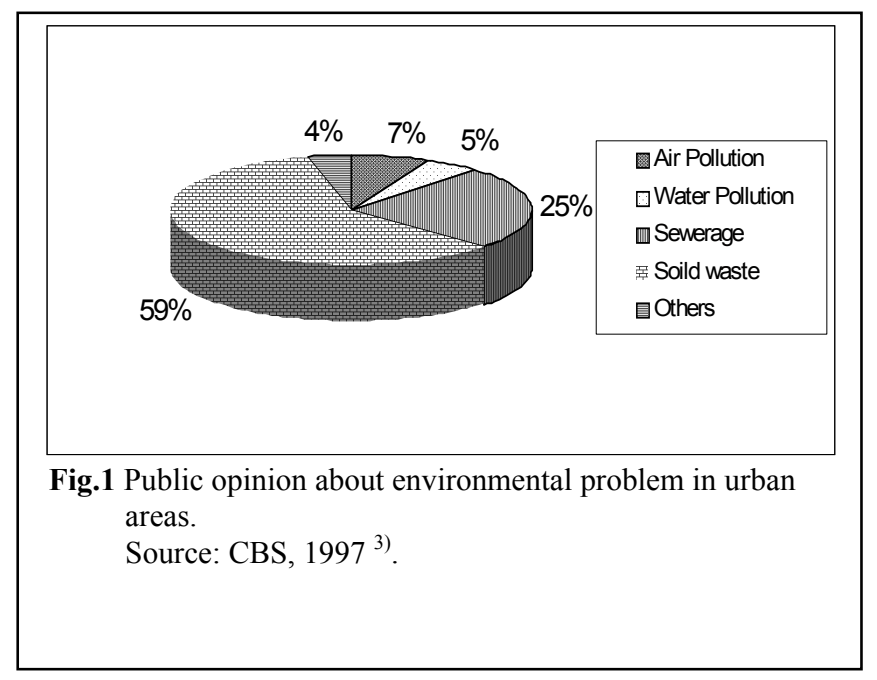

arising from unplanned urbanization. This new policy also states that national and foreign private agencies can be invited to undertake the work of solid waste management. However, this policy has not yet been effectively implemented. From the beginning of 1997, the responsibility of managing solid waste of each municipality has been handed over to the respective municipalities. But the handling and safe disposal problem of solid waste is still a big problem at Kathmandu city as well as other major cities in Nepal.

\section{(3) Present condition by solid waste}

Gokarna Landfill Site (GLFS), a first landfill site in Nepal was started at Gokarna in 1986, which was closed down in January 1994, due to local resident's opposition on environmental pollution ground. After closing down of GLFS, solid waste has been dumped at Bishnumati Corridor Dumping Area (BCDA) from the middle of 1994, and still continued over the flood plain or buried below the ground level haphazardly. Thickness of waste can be seen $3 \mathrm{~m}$ to $4 \mathrm{~m}$ in depth and width of filling varies from $10 \mathrm{~m}$ to $50 \mathrm{~m}$ as per the site condition. Protection work against river erosion is not practiced and flow of leachate into the river can easily be observed. The process of land filling is not preventing the disease vector or the emission of bad odors. Besides, solid waste has also been dumped in the corner of the public places mainly in road stray where birds and animals are scavenging garbage, littering the waste all around the locality (Fig. 2).

The water quality studied (2003-2005) ${ }^{4), 5}$ in and around GLFS and BCDA in shallow wells, springs, leachate and rivers for two years time period revealed that the impact of solid waste disposal on shallow ground water quality was still prevalent in both sites. River water quality in BCDA has been degraded due to the introduction of different types

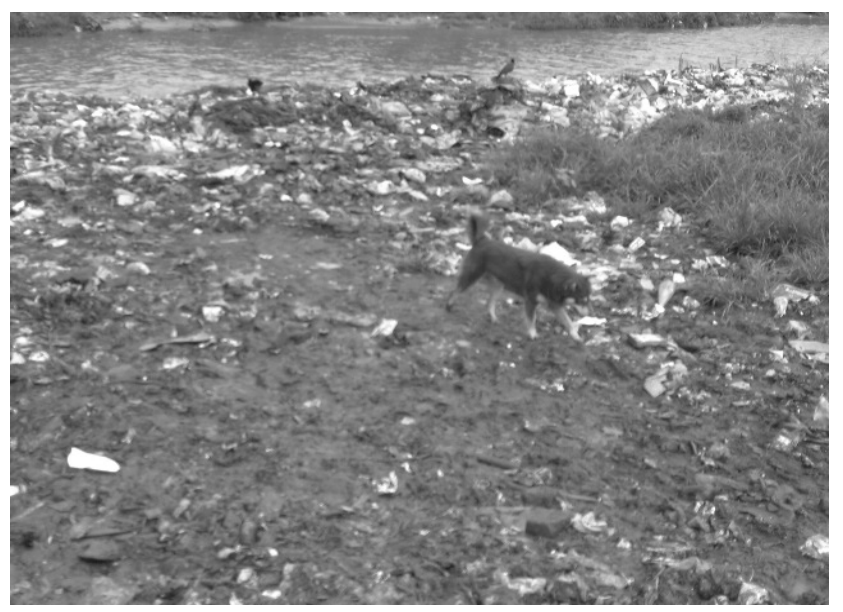

Fig. 2 Bishnumati corridors open dumping, March 2004 . 
of pollutants from solid waste into the water sources. COD level of surface water was found very high which also indicated the higher pollution contamination from dumping of waste. Degree of contamination for each monitoring wells from both locations were higher than other shallow wells of Kathmandu Valley. But water from all shallow wells from both areas was not within the drinking standard of WHO as well as for daily use. But local people are compelled to use not having another alternative.

\section{METHODOLOGY}

\section{(1) Tools used}

Various tools had been developed to effectively gather the required information (both quantitative and qualitative) from the specified target groups:

- Structured Questionnaires

- Key Informant Interviews

- Focused Group Discussion

\section{(2) Sampling procedure}

This study is completely based on primary data that is obtained from field survey during FebruaryMarch, 2005 in Kathmandu Valley(Fig.3). There were two types of specific target groups, firstly the waste generators and secondly the waste affected group. The waste generators were again divided into two groups- household and business \& industrial enterprises. In order to obtain a representative sample of the Kathmandu city, one old growth area Ason and one new growth area Koteshwor (CBS $2002)^{6)}$ were selected. To obtain representative sample, both study areas were divided into five clusters and one cluster was chosen for each area by using random sample method. Every tenth household of each cluster was surveyed until the target of 30 households was met by using systematic random sampling.

Similarly, dumped waste affected households were surveyed in two areas where water quality testing of shallow wells, springs and rivers had recently completed i.e. GLFS and BCDA. The sampling frame was constructed using voter list. By using systematic random sampling, 50 respondents from BCDA and 30 respondents from GLFS were selected. Moreover, 48 business \& industrial enterprises were selected randomly consisting mostly hotels, hospitals, nursing homes and small industries. Sampling of business \& industrial enterprises waste generators were carried out in selected pocket areas where specific industries were more concentrated. Large hospitals and industries

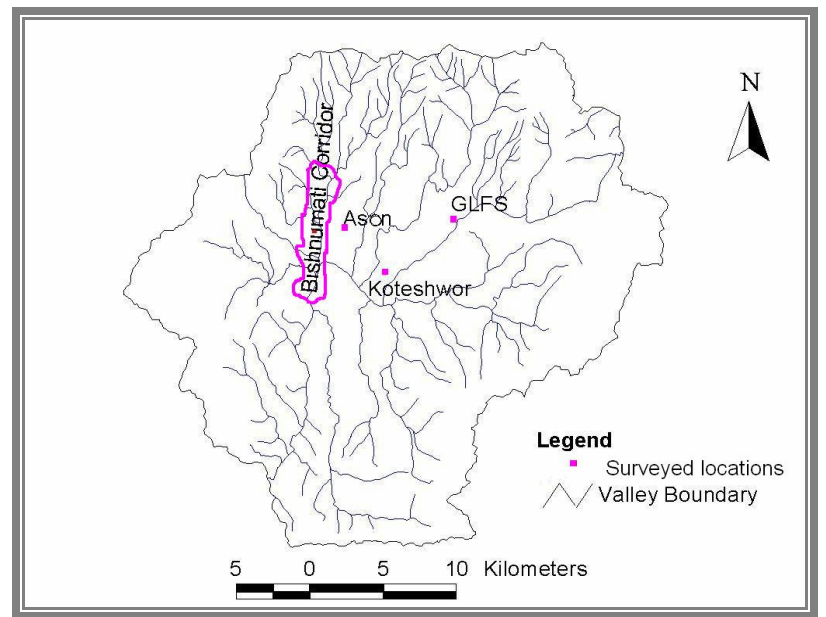

Fig. 3 Study Area at Kathmandu.

were not included in the sample as they have their own waste management strategies.

Three in-depth interviews were conducted with knowledgeable respondents regarding solid waste and management within each area to support the quantitative information and one focus group discussion was conducted within each study area to obtain qualitative information. It was envisaged that focus group discussion has the power to garner qualitative information.

The questionnaires were designated in order to collect views and perspectives of the people from waste impacted and waste generator areas. These includes opinions about awareness, values/attitude regarding waste disposal, waste reduction practices, willingness to pay for effective management, waste reuse, recycle, effects, possible mitigation measures, reclamation efforts, socio-economic status etc.

\section{(3) Analysis}

All completed questionnaires were manually coded and edited by the researcher. These were then entered into the computers using Microsoft Access Data Base. Data entry was manually crosschecked to ensure accuracy. Qualitative information was analyzed manually. All frequency and cross tabulations analysis was carried out through SPSS software.

\section{(4) Significance of the study}

The waste management system was developed over a decade (1986) in Kathmandu Valley but the problem still persists on greater scale. At present very little information exists about the impact of solid waste on health, environment, culture and heritage as well as, ground water and surface water bodies. On the contrary, no study is available on the integrated approach with technical solution in 
community centered approach for solid waste dumping issue. In this moment, this study has significance and vital role as preliminary information on the solid waste impact in and around the dumping site of GLFS and BCDA in Kathmandu with the assessment of community people's perceptions. Moreover, this study will be an advantage for the policy makers to begin management practices with a new concept in order to obtain a long term solution for the solid waste dumping issue in Kathmandu Valley.

\section{RESULT AND DISCUSSION}

As survey was carried out in two groups; the waste impacted and the waste generator, therefore results of the survey are also categorized into two headings as follows:

1. Dumped waste impacted group

2. Waste generator group

\section{(1) Dumped waste impacted group}

The dumped waste impacted group includes the households of GLFS and BCDA. Parts of key informant's interview have been reflected in Table 1 and the waste scenario and community perceptions are as follows:

\section{a) Impacts of dumped waste}

Of the total households surveyed, $93.0 \%$ of the respondents in BCDA reported that they had dumped waste impact in their area while $56.0 \%$ reported it from GLFS and this means that the situation is severe in BCDA in comparison to GLFS The basis behind it may be that, GLFS was abandoned for disposing solid waste in 1994 while BCDA is still in practice showing a disparity in results between these two areas. Prevailing effects, still in GLFS showed that the effective reclamation efforts had not taken place, however, could reduce the effects significantly.

\section{b) Water quality}

About $86.7 \%$ of the respondents in BCDA and $68.0 \%$ of the respondents in GLFS reported that dumped waste caused adverse impact on groundwater as well as surface water bodies. The response from Gokarna in community survey was a definite indication that reclamation efforts had not been entirely successful and requires further improvement in terms of drinking water as far as the community is concerned.

\section{(2) Waste generator groups}

The waste generator group includes two sub groups: the household and the business \& industrial enterprises. The attitude of community in terms of
Table 1 Sample of the key informant's interview.

1. "Due to bad smells and open waste dumping practice, none can move near the holiest river Bishnumati. Waste dumping practice near the BCDA directly impacted our cultural heritage and health condition of the people.

-Twenty-nine years old, BCDA key informant

2. "Water from tube wells as well as springs has bad odors, particularly water from shallow tube wells has tendency to transform white clothes to yellow while washing because of severe contamination.

- Key informant of BCDA area

3. "Centrally managed waste management system is not sustainable because of poor governance, poor monitoring and not involving community people as stakeholders. This has led shut down of GFFS site....

- Key informant of GLFS site

willingness to do something for solid waste management is given below:

\section{a) Household waste generators}

Waste generators participation was further classified in three categories (home level, community level and city level) in order to find out their interest, propensity and acceptance for the effective system of waste management. Community level participation for the solid waste management is to involve a single community for that area where they belong for handling of their own waste including collection and management whereas in home level; the waste is managed in household level involving by the member of each family on their own responsibility. The city level waste management is to be conducted by the larger responsible bodies such as municipalities, sewer $\&$ sanitation department or INGOs, NGOs etc. covering large areas, often one municipality or two in combination.

Respondents were asked to mention their interest in two different cases; willingness to pay and willingness to get involved to ameliorate solid waste management for the three categories and further analyzed to obtain final results.

Willingness to pay and get involved in waste management:

All areas surveyed reported that majority of the respondents $(59.1 \%)$ were willing to pay to improve the solid waste management system at home and community level. All areas indicated a lack of willingness to do so at the municipality level. This was particularly true of the two waste impacted areas that were surveyed, they were very unwilling to pay to improve the system at the municipality level, with $98.0 \%$ of the respondents in Gokarna 


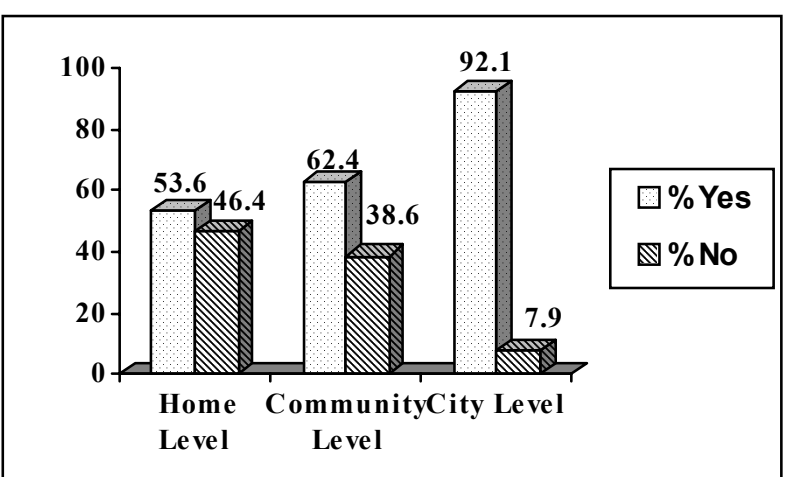

Fig.4 Willingness to pay to improve at Each Level (From Average of all four areas BCDA, GLFS, Ason, and Koteshwor).

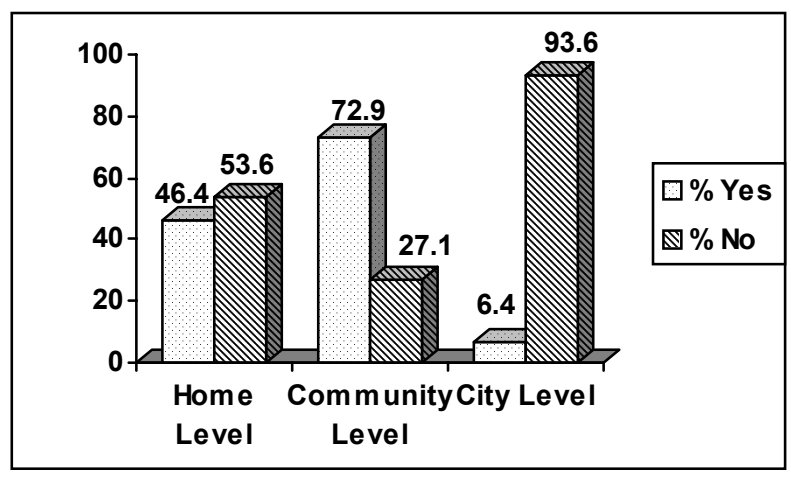

Fig.5 Willingness to get involved at Each Level (From Average of all four areas BCDA, GLFS, Ason, and Koteshwor).

saying no, and all of the respondents in BCDA with denial. However, respondents in BCDA were very willing to pay to improve the system at the community level $(83.3 \%)$, but less willing to pay to improve the system at the household level, $26.7 \%$. The respondents from GLFS had the differing idea, with $72.0 \%$ willing to pay to improve the system at the household level and only $52.0 \%$ willing to pay to improve the system at the community level.Fig.4 shows the averaged willingness to pay to improve the solid waste management system at waste generator level including all four areas BCDA, GLFS, Ason, and Koteshwor.

Respondents from all four areas reported a willingness to get involved to improve the system of solid waste management at both home and community level. The willingness to get involved at the community level was very strong in the dumped waste impacted areas, with BCDA $86.7 \%$ and $80.0 \%$ with GLFS of the respondents willing to get involved. Municipality level involvement was a total reverse, with all of the respondents in BCDA and Gokarna unwilling to get involved for the same purpose. The averaged willingness to involve in improving the solid waste management system of at

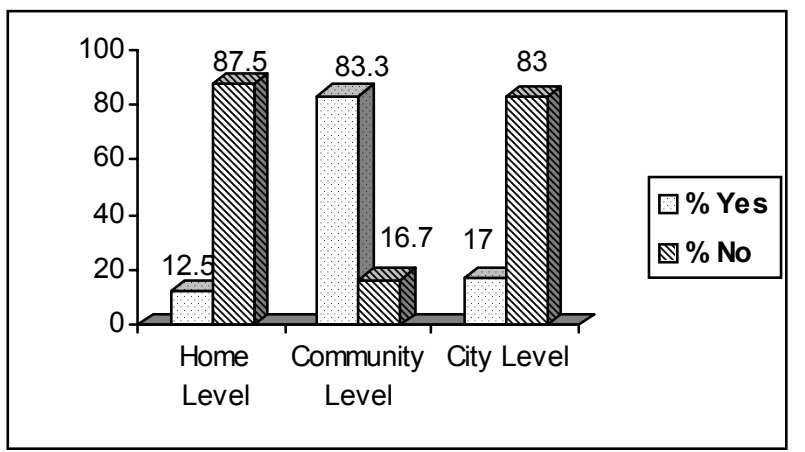

Fig.6 Willingness to pay to Improve Solid Waste Disposal at Each Level (industry).

waste generator levels including all four areas BCDA, GLFS, Ason, and Koteshwor is given in the Fig.5.

The new growth area of Koteshwor is the least willing to pay for improvements or to get involved beyond the household level, with $53.3 \%$ unwilling to become involved at the community level and $86.7 \%$ unwilling to become involved at the municipality level. Perhaps, the reason behind this could be the fact that they haven't felt the need of improvement because they are least affected by the dumped solid waste. This area generates the most waste per household, as well as the highest percentage of non-degradable wastes. Their lack of willingness in contributing or in becoming involved on improving the system of solid waste management should be investigated further.

\section{b) Business \& industrial enterprises waste generators}

The business \& industrial enterprises waste generators were also asked that whether they are willing to involve in improving the solid waste management system at home, community level and city level. The answer were analyzed as follows

Willingness to pay and get involved in waste management

Once again the willingness to pay to improve solid waste disposal at the community level is quite pronounced at $83.3 \%$. This is a reverse of the willingness to pay to improve solid waste disposal at the city level, with $83.0 \%$ reporting that they are unwilling to do so. The willingness to pay to improve solid waste disposal of the business \& industrial enterprises waste generators is shown in the Fig.6.

The willingness to get involved to improve the system of solid waste management is a carbon copy image of the willingness to pay to for improvements. The focus is very much at the community level with little willingness to get involved at the home or city levels. 


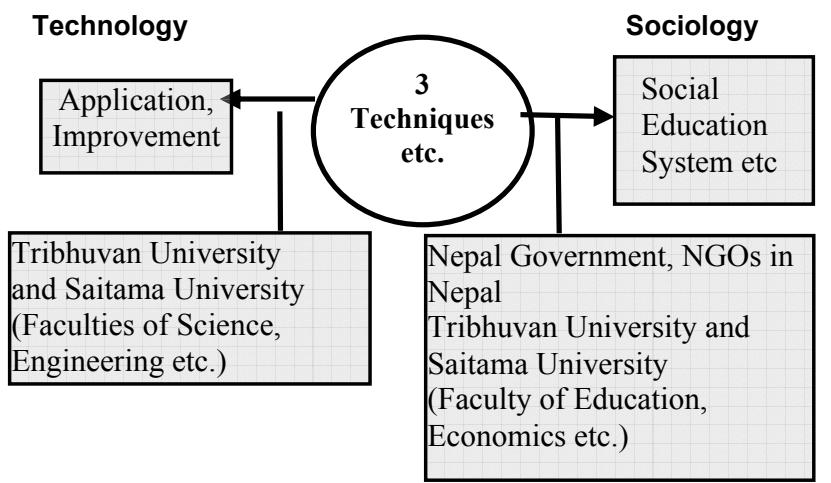

Fig.7 Unification of Technology.

\section{(3) Potential opportunities}

Watanabe ${ }^{7}$, have presented the concept on solid waste management by unification of technology with different aspects is the need for Kathmandu, Nepal. It is further elaborated and mentioned in Fig.7, where it is only possible when technology and sociology for managing waste disposal is supported by two directions of cooperative research works: the improvement and the application of the techniques and its importance; and the study on the preferable social education system.

Further Devkota et. al. ${ }^{5}$ have also discussed the possible approach based on the close affinity between administration and the community, in which, the administration makes the rules with the people, has all the people know about, own and accept the rules. Then it teaches what they have to actually do, and where it is heading. Then only finally, based on the understanding, people cooperate with the administration, they educate one another, and implement and run it together.

However, based on the discussions and findings above, it is realized that the root cause of the problem lies at the people and planning aspects, rather than the technical ones. Firstly, the Government doesn't appear to have implemented this within the context of a clear, overarching integrated environmental management policy, and with the understanding of the planning and operational responsibilities, nor did it consult with all the stakeholders, particularly the local community.

The community survey as mentioned above identified a high willingness from the communities, including industries, to pay for improvements at the home and community levels. There was also a willingness to get involved at these levels. Involvement and willingness to pay at the community level was most pronounced. This willingness on the part of the communities provides the opportunity to investigate what levels of service the people would be willing to invest in, and the amounts they would be prepared to pay for each level of service.

There was also a high willingness to become involved in the management of waste by reducing, reusing and recycling. Of particular interest in the Kathmandu environment, is the indicated willingness to use and reuse cloth bags instead of plastic. With plastic bags being one of the most visible non-biodegradable components of solid waste within the valley, there is an opportunity through education and awareness campaigns to significantly reduce the amount of plastic waste. Although the transformation of willingness into action is always a challenge, a fertile environment for recycling schemes obviously exists.

Composting of bio-degradable wastes is another area where there was a very high level of willingness to consider. Given the high percentage of biodegradable waste in the valley, $(62.3 \%$ of household waste and $57.8 \%$ of industry waste; this provides an opportunity for another significant reduction of waste at source.

\section{CONCLUSION AND RECOMMENDATION}

In summary, though waste is a behavioural issue, its management is approached simply as a technical perspective, not just in developing countries but also in the developed world. This generally ends up in grave consequences such as the problem faced by the residents of GLFS and BCDA, which cannot be easily fixed neither by the decision makers nor the residents.

The discussed research and study showed that there is high willingness to pay or get involved to improve the solid waste management system at the community level but minimal in municipality/city level. It is also inferred that the community is very much interested to pay or get involved to improve the solid waste management in community level.

Recommendations made by the respondents such as lack of awareness raising, not involvement of the community from the planning stage which resulted into community resentment, lack of ownership, environmental threats, un acceptance of infrastructure facilities (collection, transfer stations, and landfill) and possible of introducing tipping fees are not introduced but should be encouraged for sustainability of solid waste management in community level for coming days.

Finally, based on the above data, result, and discussions community-based approach is only for the successful implementation and running of landfill site without any conflicts and mismanagement. 
ACKNOWLEDGEMENT:The authors are grateful to Solid Waste Mobilization Resource Management Center (SWMRMC), people of GLFS, BCDA, Ason, Koteshwor, and industrial houses for providing the research venue and permission for publication. We also extend our sincere appreciation and thanks to IDS-Nepal Team especially Ms Michelle Karlzen, Ms Prabha Pokhrel, Mr Shekhar Koirala including enumerators for extending their help and cooperation. Similarly, the authors would like to express their sincere thanks to anonymous reviewers for their constructive comments and suggestions for the enhancement of this research paper.

\section{REFERENCES}

1) NPC: The Tenth Five-Year Plan of Nepal, National Planning Commission: Kathmandu, Nepal, 2002.
2) UNEP: The State of the Environment Report, United Nations Environment Programme 2001.

3) CBS: Central bureau of Statistics, Nepal, 1997.

4) Devkota, D.C., Watanabe, K.and Dangol, V.: Solid Waste Management Issue in Nepal-Gokarna Landfill Site and its impact on groundwater, Proceedings of seminar on Solid Waste Issue: An Environmental Problem organized by TU, Nepal and GRIS, Saitama University, Japan, pp. 47-57, Dec. 2003.

5) Devkota, D.C., Watanabe, K. and Dangol, V.: Need for Alternate Approaches in Solid Waste Management - Case Study Kathmandu Valley. Paper presented in 30 th Water, Engineering and Development Center (WEDC) Conference at Vientiane, Lao PDR Oct. pp.24-29, 2004. (Proceeding Pre-prints Published) pp.73-76, Oct. 2004.

6) CBS: Central bureau of Statistics, Nepal, 2002.

7) Watanabe, K.: Unification of Technology and Sociology for Managing Waste Disposal, Proceedings of seminar on Solid Waste Issue: An Environmental Problem organized by TU, Nepal and GRIS, Saitama University, Japan, pp. 1-9, Dec. 2003.

(Received August 11, 2005) 